\title{
Evaluating the Constraints to Development of Agricultural Insurance for Cashew Crop Farmers in Brong-Ahafo Region of Ghana
}

\author{
Nicholas Oppong Mensah"1, Simon Cudjo Fialor², Edward Yeboah ${ }^{3}$ \\ ${ }^{1}$ Department of Agricultural Economics, Agribusiness and Extension and KNUST School of Business, Kumasi, Ghana \\ ${ }^{2}$ Kwame Nkrumah University of Science and Technology (KNUST), Kumasi, Ghana \\ ${ }^{3}$ University Post Office, Kumasi, Ghana \\ Email:nicoppmens@yahoo.com,scfialor.agric@knust.edu.gh,simonfialor@yahoo.co.uk,eddie.yeboah401@gmail.com
}

How to cite this paper: Mensah, N.O., Fialor, S.C. and Yeboah, E. (2017) Evaluating the Constraints to Development of Agricultural Insurance for Cashew Crop Farmers in Brong-Ahafo Region of Ghana. Open Journal of Business and Management, 5, 215-229.

https://doi.org/10.4236/ojbm.2017.52020

Received: July 8, 2016

Accepted: April 8, 2017

Published: April 13, 2017

Copyright $\odot 2017$ by authors and Scientific Research Publishing Inc. This work is licensed under the Creative Commons Attribution International License (CC BY 4.0).

http://creativecommons.org/licenses/by/4.0/

\begin{abstract}
Research evidence from the International Institute of Tropical Agriculture (CIAT) in 2011 gives credence to the notion that cashew development would mitigate the impact of climate change on cocoa in 2012. This makes cashew development imperative, however to do so requires access to credit from financial institutions, which ration credits when it comes to lending to the agricultural sector. Research evidence has shown a correlation between agricultural insurance and loan uptake in Malawi and Ghana. However an evaluation of the cashew subsector in the Brong-Ahafo Region of Ghana with an aim of developing agricultural insurance schemes for cashew crop farmers has not been without constraints. This study sought to investigate the key constraints that would impede the development of agricultural insurance for cashew crop farmers in the BrongAhafo Region of Ghana. Based on a positivist research philosophy, the study employed quantitative techniques. A multistage sampling technique was employed, which involved purposively selecting stakeholders of Ghana Agricultural Insurance Pool (GAIP). A simple random sampling technique was also employed to select 30 pool stakeholders from GAIP. Data were collected by means of structured questionnaires. Data were analyzed by employing descriptive statistics, and the Kendall coefficient of concordance was used in identifying and analyzing the perceived constraints to developing agricultural insurance for the cashew crop farmers in the study area. The result from the survey indicated that high marketing cost; high premiums (making the product unaffordable); lack of agricultural insurance legislation; low availability of data; lack of knowledge about product development; and lack of qualified personnel in the area of agricultural insurance were some of the perceived constraints that would impede the development of agricultural insurance in the study area. Thus a Public Private Partnership
\end{abstract}


approach, as well as research and development, is imperative to overcome the financial, marketing, institutional, technical data, human resources and legal constraints to agricultural insurance and cashew development in the study area.

\section{Keywords}

Agricultural Insurance, Constraints, Suggestions for Insurance Uptake

\section{Introduction}

Agriculture is critical to the development of Africa. Over 70\% of Africa's population depends on agriculture [1]. In Ghana, the agricultural sector represents one of the most important sectors in the economy and is paramount to achieving food security and poverty reduction. This stems from the fact that out of a total land area of 23,853,900 hectares (ha) in Ghana, the potential land for agricultural production is $13,628,179$ ha representing (57\%). Out of this only $7,311,500$ ha, representing $54 \%$ of agricultural land is cultivated, and 29,804 ha reflecting $(0.2 \%)$ are irrigated farmlands. The rest are largely rain fed [1] and [2]. This brings to the fore the risk in Ghana's agriculture productivity, as it remains largely rain fed and vulnerable to a range of climatic hazards notably droughts, erratic rainfall, floods, as well as bushfires and localized windstorms. The ramifications of these factors manifested in Ghana as adverse weather conditions, especially in years like 1983, 1997, 2002, 2007 and 2009 where droughts, floods and bush fires severely affected several places in Ghana. Such perils usually cause severe damages to food crops like maize and rice as well as cash crops like cocoa, mango, banana and cashew plantations resulting in the decline of agricultural productivity [3]. Although cashew can better withstand these hardships [4], there are varied viewpoints that account for the different reasons given for this productivity decline.

Over the years, farmers in developing countries, including cashew farmers in Ghana, have been managing and coping with the risk of the weather, pests and disease and other social perils, ex-ante and post-ex post, using traditional methods that are sub-optimal [5]. These methods are not effective in addressing covariate risks such as drought and other climate change related risks that are threats to farmers in sub-Saharan Africa [6]. Moreover, traditional risk management strategies such as diversification, farm fragmentation and asset flexibility fail to provide an adequate safety net against high-impact, low frequency and covariate risks that tend to undermine kin support networks and other coping mechanisms [7].

Admittedly, these traditional methods enumerated are not attractive to financial institutions causing them to enact a tighter lending policy in the form of credit rationing. However, in developed economies, protection against financial impacts is normally done through the purchase of a risk management instru- 
ment, prominent among them being agricultural insurance [8]. Moreover, researchers such as Giné and Yang [9], Stutley [3] and Magnoni et al. [10] have shown a correlation between agricultural insurance and loan uptake in Malawi and Ghana; however, the development of agricultural insurance schemes for cashew crop farmers has not been without constraints. In view of this, the study sought to find the constraints to the development of agricultural insurance products for the cashew farmers in the Brong Ahafo Region of Ghana, which is the study area.

\section{Brief Literature Review}

The agricultural insurance market faces constraints worldwide and the situation in Ghana may not be different; however, empirical literature on the constraints faced by Ghana Agricultural Insurance Pool (GAIP) is scanty. Some empirical literature has illuminated the types of constraints faced by agricultural insurance schemes from both the insurer and the farmers' perspective. A related study by Qingshui and Xuewei [11] identified a range of constraints to the development of insurance, which include high loss ratio; fewer sources of income subsequently weakening farmers' purchasing power of insurance products; inadequate promotion of agricultural insurance knowledge leading to vague evaluation of farmers; lack of policies supporting agricultural insurance development; and lack of agricultural legislation.

Tsikirayi et al. [12] amplified these constraints in a similar study of the Zimbabwe agricultural insurance sector from both the farmers and insurers' perspective, and echoed in their findings that farmers view insurance as an unnecessary expense rather than an investment to curtail future risk, especially small holders. They were of the view that farmers were not aware of its benefits, and identified low participation by farmers due to high premium charged by the insurance company making it unaffordable to them. They also identified factors such as limited knowledge; negative perceptions of insurance in general; poor service quality delivery; low agricultural production; and remoteness of insurance companies. Meanwhile insurers viewed the constraints to agricultural insurance uptake as lack of affordability; distance of the service provider from the farming enterprises; and the negative effect of location affected both parties.

Empirical studies by Abdulmalik et al. [13] analyzed the Nigerian agricultural insurance industry and amplified some of the constraints encountered by the farmers under an agricultural insurance scheme as inadequate with delayed payment of claims which in turn brought about a negative perception of agricultural insurance benefits. The farmers tended to believe that insurance companies are only interested in collecting premiums but not paying claims. Moreover, administrative constraints as a result of bureaucracy were echoed as one of the constraints faced by farmers in participating in agricultural insurance and this had the tendency to influence farmers to withdraw from insurance schemes. Other constraints enumerated by the study included cumbersome claim settlement procedures that include delays, difficulty in accessing insurance personnel 
and inadequate information dissemination.

In the Zimbabwean insurance industry, Yusuf [14] documented some constraints as low penetration of the scheme; scarcity of data for actuarial determination of important underwriting; high moral hazards; lack of qualified personnel in the area of agricultural insurance; low participation of commercial banks in agricultural finance; and inadequate agricultural infrastructure.

Similarly, Mahul and Stutley [15] identified low penetration in government sponsored programs in appropriate pricing; poor financial performance with claims cost and administration cost exceeding premium; and uncontrollable moral hazards.

In the Caribbean and Latin America, Wenner [16] assessed the constraints to development of agricultural insurance and observed lack of statistical independence; asymmetric information; high administrative costs; and a mismatch between farm preference and capacity to pay. Inadequate legal and regulatory frameworks, distorted government incentives and reluctance of reinsurers to enter the market were the developmental constraints facing agricultural insurance markets in the aforementioned areas.

Other constraints include poor regulatory framework; low awareness; small size of market; financial literacy; high marketing cost; lack of knowledge about product development and marketing channels [3]; lack of government involvement in agricultural insurance; data availability; basis risk; and limited demand in Ghana. Cross [17], leaning on Fin Mark Trust [18], noted that prospective clients' microfinance have no idea of the processes involved in purchasing insurance apart from lack of affordability on the part of some of their respondents in Ghana.

Arguably, apart from information asymmetry and lack of data, it can be concluded that the constraints to the development of most agricultural insurance schemes are financial, administrative, institutional and marketing constraints.

There are several methods for testing rankings of factors. From literature some ranking techniques identified are Pearson's correlation coefficient; the Spearman rank correlation; Garrett's ranking techniques; Friedman's two-way analysis of variance; and Kendall's coefficient of concordance. Pearson's correlation is used for interval data, but if normal distribution of variables being considered is in ranks thus be it interval or ordinal the Spearman rank correlation or Kendall's correlation coefficient can be used. There is, however, a close relation between Friedman's test and Kendall's coefficient of concordance [19]. This addresses the hypotheses concerning the same data and the use of the Chi square test. However, they differ in the formulation of their respective hypothesis. Whereas Friedman's test focuses on the items being ranked, the hypothesis of Kendall's test focuses on the rankers themselves. Garrett's ranking score techniques, on the other hand, uses the average score of the rankers and arranges them in either ascending or descending order.

The disadvantage of the Garrett's ranking technique is that it involves several steps and does not test the level of agreements between rankers. Kendall's coeffi- 
cient of concordance is employed for this study because the Kendall's ( $\left.W^{a}\right)$ provides the test of agreement of the rankers (respondents) among their rankings, which the Friedman's and Garrett's test lack.

The Kendall's coefficient of concordance measures the strength of relation in a direct and easily understood way. The Kendall's coefficient has an intuitively simple interpretation and simpler than Spearman coefficient. It can be computed from the actual observation without first converting them to ranks [20]. The Kendall's coefficient of concordance measures the degree of agreement among rankers on a number of constraints ranked. Kendall's coefficient of concordance is an index that measures the ratio of the observed variance of the sum of ranks to the maximum possible variance of sum of ranks [21].

\section{Methodology}

Based on a positivist research philosophy, the study employed quantitative techniques. A multistage sampling technique was adopted in this study. The first stage involved purposively selecting stakeholders of GAIP as the study population. The second stage involved the utilization of the simple random sampling technique to select 30 pool stakeholders from Ghana Agricultural Insurance Pool (GAIP) by the aid of a list and application of the lottery method.Various insurance approaches are normally used to take care of cashew farmers' residual risks which were both systematic and idiosyncratic in theory and practise. The insurance approaches were modelled in a hypothetical setting and presented to the supply side: which are the pool stake holders of Ghana Agricultural insurance pool made up of the management board, technical management unit, and technical committee of Agricultural insurance as well as the steering committee of the Ghana Agricultural Insurance pool (GAIP). In the study indemnity insurance products which are based on actual loss on the farm, both qualitative and quantitative losses were presented to the respondents in a hypothetical setting. Index which is based on pre-defined threshold triggers of some indexes based on some key perils such as, wind speed, temperature and excess rainfall were also presented. Simulation insurance model which has elements of systematic and idiosyncratic risk were also designed and presented to the respondents. Moreover, hypothetical insurance products based on benchmarking approach which is based on selection benchmarks site and monitored for key perils such as fire, excess rainfall, high temperature and high wind speed which were cashew farmers' residual risks were also presented. Finally unique hypothetical products which had elements of all these approaches known as functional synthesis products were also modelled and presented to the respondents. The results are as shown in Figure 1.

Data were collected by means of structured questionnaires. Data were analyzed by employing descriptive statistics. Kendall's coefficient of concordance was used in identifying and analyzing the perceived constraints to developing agricultural insurance for the cashew crop farmers in the study area.

This analysis is a statistical procedure through which the degree of agreement/ 


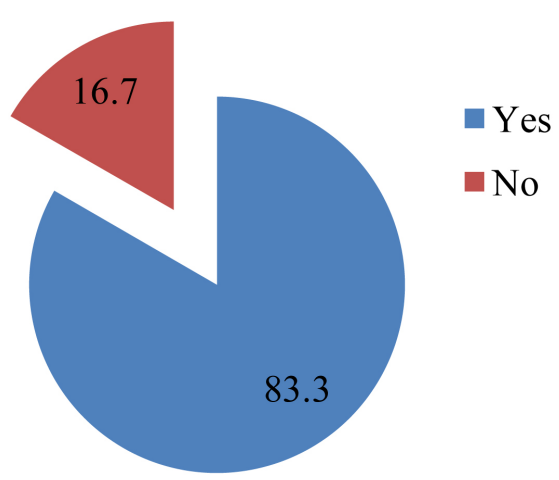

Figure 1. Pool stakeholders willingness to design agricultural insurance for cashew farmers. Source: Field Survey, 2014.

concordance between a given set of constraint/problems identified are ranked from the most pressing constraint/problem to the least pressing one measured. The identified constraints/problems are ranked according to the most pressing to the least pressing using numerals; $1,2,3,4, \cdots n$, in that order. Computing the total rank score for each problem, the problem with the least score is ranked as the most pressing, whilst the one with the highest score is ranked as the least pressing problem. The rank scores computed are then used to calculate the coefficient of concordance $(W)$ to obtain the degree of agreement in the rankings.

The coefficient of concordance $(W)$ ranges from zero (0) to one (1). It will be 1 when the ranks assigned by each farmer are exactly the same as those assigned by other farmers and it will be 0 when there is a maximum disagreement among the farmers. If $T$ represents the sum of ranks for each constraint/problem being ranked, the variance of the sum of ranks is found by the formula

$$
\operatorname{Var}_{T}=\frac{\left(\sum T^{2}-\sum T^{2}\right) / n}{n}
$$

The maximum variance of $T$ is then given by

$$
m^{2}\left(n^{2}-1\right) / 12
$$

where " $m$ " is the set of rankers (farmers) and " $n$ " is the number of constraints/ problems being ranked the formula for the coefficient of concordance $(W)$ is then given by

$$
W=\frac{\left(\left(\sum T^{2}-\sum T^{2}\right) / n\right) n}{m^{2}\left(n^{2}-1\right) / 12}
$$

Then is simplified as

$$
\frac{12\left[\left(\sum T^{2}-\sum T^{2}\right) / n\right]}{n m^{2}\left(n^{2}-1\right)}
$$

where: $T=$ the sum of ranks for each constraint

$m=$ the number of rankers (farmers)

$n=$ the number of constraints being ranked 
Hypothesis and significant test for $W:(F-$ Test $)$

$H_{0}$ : There is no agreement among the rankings of the constraints by the farmers

$H_{A}$ : There is an agreement among the rankings of the constraints by the farmers

where $H_{0}$ and $H_{A}$ denote null and alternate hypotheses respectively.

The coefficient of concordance $(W)$ may be tested for significance in terms of the $F$-distribution.

The $F$-ratio is given by

$$
F-\text { ratio }=\frac{[(m-1) W c]}{(1-W c)}
$$

$W c$ is the calculated Kendall's Coefficient of Concordance $(W)[20]$.

\section{Results and Discussion}

Table 1 above shows that of the total (30) sampled respondents, 21 (70\%) were between the ages of 30 - 40 years and $9(30 \%)$ were between the ages of $41-50$ years. Majority of the respondents were females (83\%) and males were (17\%), which is consistent with proportion of sex ratio of the population in the insurance sector. About $87 \%$ of the respondents were married and $13 \%$ were single. Also, Christians were majority of the respondents (80\%) and 20\% were Muslims. The results from Table 1 further indicate that all the respondents had tertiary

Table 1. Socioeconomic characteristics of respondents.

\begin{tabular}{ccc}
\hline Variable & Frequency & Percentage \\
\hline Age & 21 & 70 \\
$30-40$ & 9 & 30 \\
$41-50$ & 5 & 16.67 \\
Sex & 25 & 83.33 \\
Male & & \\
Female & 26 & 86.67 \\
Marital status & 4 & 13.33 \\
Married & & \\
Single & 24 & 80 \\
Religion & 6 & 20 \\
Christian & & 100 \\
Muslim & 30 & \\
Educational Background & & 90 \\
Tertiary & 20 & 10 \\
Work Experience & 10 & \\
$10-20$ & & \\
$21-30$ & &
\end{tabular}

Source: Authors computation. 
education. However, Majority (90\%) of the respondents had between $10-20$ years and 10\% had 21 - 30 years working experience in the insurance sector.

Pool stakeholders' willingness to design agricultural insurance for cashew farmers and their financiers is shown in Figure 1.

The results from Figure 1 above indicate that most of the insurance pool stakeholders are ready and willing to design agricultural insurance for cashew farmers in the study area with about $83 \%$ whiles only about $17 \%$ were not willing to design insurance packages for farmers.

In Figure 2, the insurance pool stakeholders were asked to indicate the approach they would prefer in providing agricultural insurance for cashew crop farmers. The results show that $83.5 \%$ were willing to design indemnity insurance for farmers whereas $16.5 \%$ were not willing to design indemnity insurance. Likewise, $66.7 \%$ were willing to design index and simulation insurance whereas $33.7 \%$ were not willing to design either index or simulation insurance. For both benchmarking and functional synthesis, $33.7 \%$ were willing to design products based on these approaches for cashew farmers in the study area. In all, the results imply that agricultural insurance pool stakeholders have higher preference for designing indemnity approach similar to the financial institutions' preferences for insurance products.

These preferences have their requirements in terms of operational cost, as on farm inspection is a pre-requisite in event of claims to provide compensations that would bring the farmer to their pre loss financial position (Indemnity Principle).

This requires risk mapping to determine the Maximum Probable Loss (MPL) [3] whereas with the index, purchase of satellite data is a pre-requisite for satellite index and an MOU with Ghana Meteorological agency to supply data is crucial for weather index insurance products [22].

Moreover, the choice of these approaches have their implication for reinsurance treaties with reinsurers, as reinsurers prefer volumes of business and in situations where the business volumes are small reinsurers would want to take higher quota of the risk in the treaties and that also has implication for premium

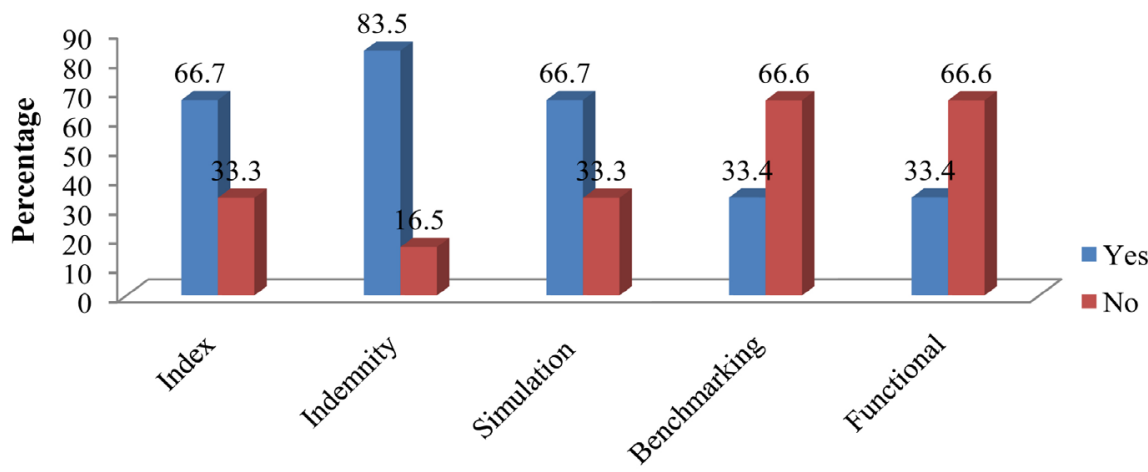

Insurance Approach

Figure 2. Pool stakeholders interest in various agricultural insurance approaches. Source: Field Survey, 2014. 
flight as most of the premium paid goes to the reinsurer, particularly when they are outside the country [23].

Pool stakeholder preference for designing insurance product option can be seen in Figure 3.

The results as indicated in Figure 3 showed that $50 \%$ of the pool stakeholders were willing to design 50\% of Option C of Index which is Area Yield Index, and

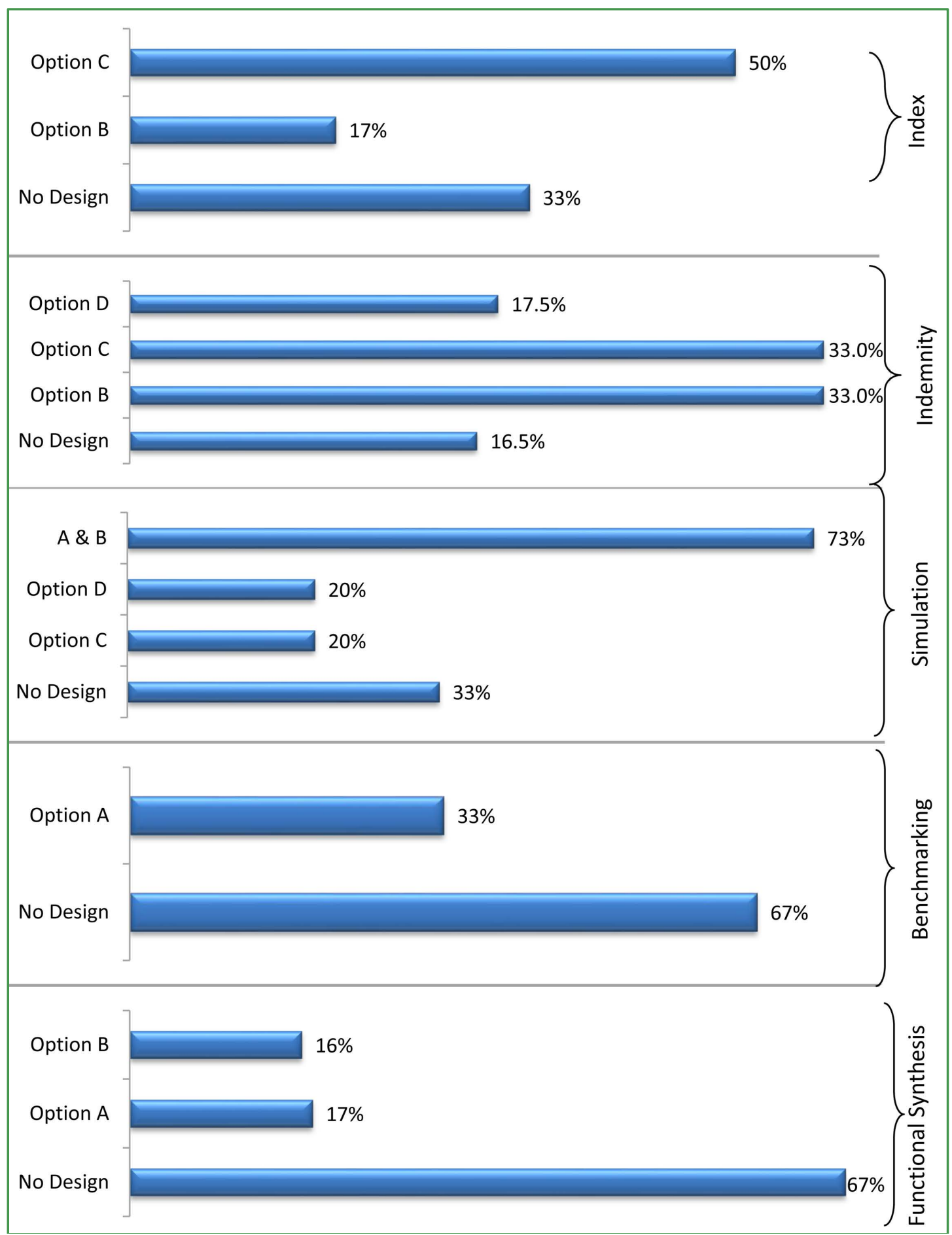

Figure 3. Pool stakeholders interest in designing insurance product option. Source: Field Survey, 2014. 
$17 \%$ were willing to design Option B which is Satellite Index insurance products. With regards to Indemnity product options, none of the stakeholders were willing to design options A which is named single peril for fire; $33 \%$ were willing to design option $\mathrm{B}$ which is named peril damaged base for high wind speed; $33 \%$ were also willing to design option $\mathrm{C}$ which is also named peril damage base product for excess rain fall; and only $17.5 \%$ were willing to design option $D$ which is Multiperil Crop Insurance product for high temperature, excess rainfall and high wind speed. Preference for designing Simulation Approach Product Options among the agricultural insurance pool stakeholders follows: $33 \%$ were willing to design option A which is Simulated Weather Multiperil Product for fire, high temperature and excess rainfall and high wind speed, while $67 \%$ were not willing to design option B which is Simulated Satellite Multiperil Product for fire, high temperature and excess rainfall and high wind speed. They were also not willing to design option C and D which are Simulated Area Yield index Multiperil product for fire, high temperature and excess rainfall and Indemnity and Benchmarking Simulated product for fire, high temperature and excess rainfall and high wind speed respectively. With regards to Benchmarking product, $33 \%$ were not willing to design these products as they indicated they would need further training to design the product, none were willing to design option A which is Named peril damage based and yield-based Multiperil benchmark product for fire, high temperature, excess rainfall, and high wind speed. $27 \%$ of pool stakeholders had preference for designing option B which Named Peril damaged base benchmark product for fire and $20 \%$ had preference for designing option C which is Named peril damaged benchmark product for high wind speed. Functional synthesis approach also had low utilities, which are 17\% preference for option A, which is Weather Synthesized Simulated Multiperil Insurance for damage and yield-based for fire, high temperature, excess rainfall and high wind speed, and $16 \%$ were willing to design option B which is Satellite Synthesized Simulated Multiperil insurance for damage and yield base for fire, high temperature and excess rainfall.

From the Ghana Agricultural Insurance Pool stakeholders' perspective, a myriad of perceived constraints faced the development of agricultural insurance for cashew crop farmers in the study area. The perceived constraints identified in the study were ranked in terms of severity and presented in Table 2 . The results show that high marketing cost was the most pressing perceived constraint to the development of agricultural insurance for cashew crop farmers in the study area with the highest mean score of 4.83 . The second highest constraint was found to be low collaboration with financial institutions with a mean score 4.67 , necessitating the need for a value chain financing approach with the insurance as linkage in the chain to absorb all residual risks or key perils.

The third most pressing constraint was lack of agricultural legislation with a mean score of 4.63. This is consistent with the observation made by Qingshui and Xuewei [11] who reported a lack of policies supporting agricultural insurance development and a lack of agricultural legislation as constraints to the 
Table 2. Perceived constraints to the development of agricultural insurance in the study area.

\begin{tabular}{|c|c|c|}
\hline Constraints to Development of Agricultural Insurance & $\begin{array}{l}\text { Mean } \\
\text { Score }\end{array}$ & Rank \\
\hline High premiums making it unaffordable & 4.57 & $4^{\text {th }}$ \\
\hline False claims & 1.30 & $19^{\text {th }}$ \\
\hline High loss ratio & 2.07 & $17^{\text {th }}$ \\
\hline Lack of policies supporting agricultural insurance development & 4.47 & $6^{\text {th }}$ \\
\hline Lack of agricultural insurance legislation & 4.63 & $3^{\text {rd }}$ \\
\hline Limited knowledge making farmers unaware of its benefits & 4.17 & $9^{\text {th }}$ \\
\hline Negative perceptions of insurance in general & 4.03 & $10^{\text {th }}$ \\
\hline Low agricultural production & 2.30 & $16^{\text {th }}$ \\
\hline High administrative costs & 4.10 & $11^{\text {th }}$ \\
\hline Small size of market & 1.97 & $18^{\text {th }}$ \\
\hline Lack of knowledge on how to purchase insurance & 3.17 & $12^{\text {th }}$ \\
\hline Lack of knowledge about product development & 4.47 & $6^{\text {th }}$ \\
\hline High marketing cost & 4.83 & $1^{\text {st }}$ \\
\hline Lack of knowledge on marketing channels & 4.30 & $8^{\text {th }}$ \\
\hline Low availability of data & 4.40 & $7^{\text {th }}$ \\
\hline Basis risk & 2.57 & $14^{\text {th }}$ \\
\hline Limited demand & 2.33 & $15^{\text {th }}$ \\
\hline Low participation of commercial banks & 4.67 & $2^{\text {nd }}$ \\
\hline Scarcity of data for actuarial determination of important underwriting & 4.47 & $6^{\text {th }}$ \\
\hline Lack of qualified personnel in the area of agricultural insurance & 4.50 & $5^{\text {th }}$ \\
\hline $\begin{array}{l}\text { Belief that insurance companies are only interested in } \\
\text { collecting premium and not paying claims }\end{array}$ & 2.80 & $13^{\text {th }}$ \\
\hline $\mathrm{N}$ & 30 & \\
\hline Kendall's W & 0.616 & \\
\hline $\begin{array}{c}\text { Chi-Square } \\
\text { df }\end{array}$ & 153.995 & \\
\hline Asymp. Sig & 200.000 & \\
\hline
\end{tabular}

Source: Field Survey, 2014.

development of agricultural insurance in China.

This implies that the National Insurance Commission and Parliament should come out with legislation on agricultural insurance in order to enact laws aimed at enforcing agricultural insurance contracts in the country. High premiums making agricultural insurance products unaffordable was ranked as the fourth highest constraint with a mean score of 4.57 , while lack of qualified personnel in the area of agricultural insurance in the Ghanaian insurance industry was viewed as the fifth highest constraint with a mean score of 4.50. Yusuf [14] in a similar study of the Zimbabwean observed the lack of qualified agricultural insurance personnel in Zimbabwe. This is a challenge for Ghana Insurance College and other tertiary institutions to inculcate agricultural insurance into their insurance curriculum to address this labour or human resource constraint. 
The sixth most pressing constraints were found to be scarcity of data for determining actuarially fair premium through sound underwriting as well as lack of knowledge about product development with a mean score of 4.47, while lack of education on the benefit of agricultural insurance was ranked the seventh highest constraint with a mean score of 4.40 . The issue of scarcity of data was reported by Stutley [3] in his crop insurance feasibility studies in the Ghana. Moreover, lack of knowledge on marketing channels, limited knowledge making farmers unaware of its benefits, and negative perceptions about insurance in general where ranked the eighth, ninth and tenth perceived constraints respectively with means scores of 4.30, 4.17 and 4.03 respectively. Wenner [16] also identified lack of knowledge about product development and marketing channels as constraints to the development of agricultural insurance markets in the Caribbean and Latin America.

The perceived negative perception of insurance in general is supportive of the study done by Abdulmalik et al. [13] on the Nigeria agricultural insurance set up. It is instructive to note that the perceived constraints to the development of agricultural insurance can be grouped under financial, marketing, technical, data, human resource or labour and legal constraints. The Kendall's $(W)$ coefficient of 0.616 implies that there is $62 \%$ agreement among respondents in ranking the constraints.

In order to overcome the perceived constraints so as to establish a vibrant agricultural insurance system for cashew crop farmers in the study area, suggestions to overcome the key constraints unexpectedly prove these fascinating suggestions as indicated in Table 3.

Table 3. Suggestion for agricultural insurance uptake in the study area.

\begin{tabular}{|c|c|c|}
\hline Suggestion to improve uptake & Mean Score & Rank \\
\hline $\begin{array}{c}\text { Improve farmers' awareness on the importance of insurance } \\
\text { through education and marketing }\end{array}$ & 4.97 & $1^{\text {st }}$ \\
\hline Aggregators to purchase insurance on behalf of farmers & 3.90 & $5^{\text {th }}$ \\
\hline Insurers to locate close to farmers & 3.13 & $6^{\text {th }}$ \\
\hline $\begin{array}{l}\text { Increased agricultural production that provides an agricultural } \\
\text { pool to form the basis for affordable premium }\end{array}$ & 1.43 & $8^{\text {th }}$ \\
\hline $\begin{array}{l}\text { Research and development to develop insurance products that are } \\
\text { affordable to farmers }\end{array}$ & 4.60 & $3^{\text {rd }}$ \\
\hline Law on agricultural insurance contract enforcement & 4.43 & $4^{\text {th }}$ \\
\hline Simplification of the claim process & 2.83 & $7^{\text {th }}$ \\
\hline Government intervention & 4.43 & $4^{\text {th }}$ \\
\hline Cooperation with financial institutions & 4.70 & $2^{\text {nd }}$ \\
\hline $\mathrm{N}$ & 30 & \\
\hline Kendall's W & 0.642 & \\
\hline $\begin{array}{l}\text { Chi-Square } \\
\text { df }\end{array}$ & 153.995 & \\
\hline Asymp. Sig & 8.000 & \\
\hline
\end{tabular}

Source: Field Survey, 2014 
As shown in Table 3 above, improve farmers' awareness on the importance of insurance through education and marketing ranked highest and first with a mean score of 4.97. This is consistent with Qingshui and Xuewei [11]. The next suggestion was cooperation with financial institutions with a mean score of 4.70 . Undoubtedly, this reflects the need to develop bank assurance as indicated earlier on in the model for supplying agricultural insurance in the study area. The third suggestion to improve insurance uptake is the need for pool stakeholders to leverage on research and development to develop insurance products that are affordable to a farmer, with a mean score of 4.60. Law on agricultural insurance contract enforcement and aggregators to purchase the insurance on behalf of farmers in addition to Government intervention was ranked as the fourth and fifth highest suggestion for insurance uptake with mean scores of 4.43 and 4.60 respectively. Insurers to locate close to farmers in the study area and simplification of insurance process were ranked as the sixth and seventh suggestion for increasing insurance penetration in the study area with mean scores of 3.13 and 2.83 respectively. From the foregoing, agricultural insurance penetration could be increased through research, education, strategic alliance with financial institutions and aggregators and finally government intervention and enactment of agricultural insurance laws to enforce agricultural insurance contracts. The Kendall's (W) coefficient of 0.642 implies that there is $64 \%$ agreement among respondents in terms of ranking the suggestion for agricultural insurance uptake in the study area.

\section{Conclusions and Policy Implications}

\subsection{Conclusions}

The results of this study made it explicit that key constraints to the development of agricultural insurance for cashew crop farmers in the study area include lack of data; lack of agricultural insurance legislation; lack of knowledge on product development; lack of personnel with knowledge in agricultural insurance; as well as lack of knowledge on marketing channels among others. These constraints can be grouped under financial, marketing, technical, data, human resource or labour, and legal constraints.

Constraints to agricultural insurance development were seen as lack of knowledge on agricultural insurance channels and product development, lack of data as well as lack of collaboration with financial institutions, whereas lack of credits, processors, lack of cashew marketing board and inadequate training were identified as the main constraints to cashew development in the study area. Based on the findings of the study, the following insightful policies are prescribed for stakeholders' attention, consideration and implementation.

\subsection{Policy Implications}

In order to overcome the noted constraints (apart from education and sensitization of farmers on the benefits of agricultural insurance), the results indicated that collaboration with financial institutions and other aggregators in addition to 
government interventions is key. The results also revealed the need to embark on research for agricultural insurance product development. The result from the survey indicated that high marketing cost; high premiums (making the product unaffordable); lack of agricultural insurance legislation; low availability of data; lack of knowledge about product development; and lack of qualified personnel in the area of agricultural insurance were some of the perceived constraints that impede the development of agricultural insurance in the study area. Thus, a Public Private Partnership (PPP) approach is imperative to overcome the financial, marketing, institutional and technical data, human resource and legal constraints to agricultural insurance and cashew development in the study area. The results also revealed a lack of qualified personnel in the area of agricultural insurance in the insurance industry. In this regard, agricultural insurance should be inculcated into tertiary institutions' insurance curriculum. Moreover, the suggestion for agricultural insurance uptake brought to the fore that government interventions, the mediating role of aggregators as well as laws on enforcement of agricultural insurance contract would improve agricultural insurance uptake with a positive externality effect on cashew development.

\section{References}

[1] IFDC (2013) Quality Inputs, Better Yields and More Profits. 2nd Annual Northern Ghana Pre-Season Networking Forum, Tamale Ghana.

[2] MOFA-SRID (2011) Agriculture in Ghana: Facts and Figures. Accra, Ghana.

[3] Stutley, C. (2010) Innovative Insurance Products for the Adaptation to Climate Change (IIPACC).

[4] CIAT (2011) Predicting the Impact of Climate Change on Cashew Growing Regions in Ghana and Côte d'Ivoire. Climate Change and Food Security, 1-2.

[5] Ben-Houassa, E.K. (2010) Risk, Risk Aversion and Choice of Risk Management Strategies by Cocoa Farmers in Western Côte d'Ivoire. University of Cocody, AERC Collaborative PhD Programme.

[6] Hazell, P., Anderson, J., Balzer, N., Clemmensen, A.H., Hess, U. and Rispoli, F. (2010) The Potential for Scale and Sustainability in Weather Index Insurance for Agriculture and Rural Livelihoods. IFAD, Quintily, Rome.

[7] Skees, J. (2009) The Potential for, and Uses of, Weather Index Insurance. Global Ag Risk, Inc., Atlanta, Georgia.

[8] Miranda, M.J. and Farrin, K. (2012) Index Insurance for Developing Countries. Applied Economic Perspectives and Policy, 34, 391-427.

https://doi.org/10.1093/aepp/pps031

[9] Giné, X. and Yang, D. (2009) Insurance, Credit and Technology Adoption: Field Experimental Evidence from Malawi. Journal of Development Economics, 89, 1-11.

[10] Magnoni, B., Chandam, T. and Zimnerman, E. (2002) Assessing the Client Value of Property Insurance in Ghana. Nie and GIZP, Accra, 125-127.

[11] Feng, Q.S.. and Zhang, X.W. (2010) Development Strategies on Agricultural Insurance under the Building of New Countryside. Agriculture and Agricultural Science Procedia, 1, 13-23.

[12] Tsikirayi, C.M.R., Makoni, E. and Matiza, J. (nd) Analysis of the Uptake of Agricultural Insurance Services by the Agricultural Sector in Zimbabwe. Journal of In- 
ternational Business and Cultural Studies.

[13] Abdulmalik, R.O., Oyinbo, O. and Sami, R.A. (2013) Determinants of Crop Farmers Participation in Agricultural Insurance in the Federal Capital Territory, Abuja, Nigeria. Greener Journal of Agricultural Sciences, 3, 21-26.

[14] Yusuf, K.K. (2010) Insurance Options in Risk Management in Agriculture Finance. Being the full text of paper presented on the occasion of the AFRACA Conference in Abuja.

[15] Mahul, O. and Stutley, C. (2010) Government Support of Agricultural Insurance Challenges and Option for Developing Countries. Vol. 1, The International Bank for Reconstruction and Development/The World Bank, Washington DC. https://doi.org/10.1596/978-0-8213-8217-2

[16] Wenner, M. (2005) Agricultural Insurance Revisited: New Developments and Perspectives in Latin American and Carribean. Rural Development Unit Inter-American Development Bank, Washington DC, 1-61.

[17] Cross, P. (2012) Succeeding with Mass-Market Microinsurance-The Experience of Micro. Ensure, 165-175.

[18] Fin Mark Trust (2010) Finscope Ghana. Finmark Trust, Johannesburg.

[19] Legendre, P. (2005) Species Associations: The Kendall Coefficient of Concordance Revisited. Journal of Agricultural, Biological, and Environmental Statistics, 10, 226 245. https://doi.org/10.1198/108571105X46642

[20] Edwards A.L. (1964) Statistical Methods for the Behavioural Sciences. Holt Rinehart and Winston, New York, 402, 410.

[21] Mattson, D.E. (1986) Statistics-Difficult Concept of Understanding Explanations. Bolechanzy Carducci Publishers Inc., 281, 361, 423.

[22] Matthias, G. (2012) Review of Satellite Based Rain Estimates Suitable for GAIP \& Evaluation of the Basis Risk for the 2011 Maize Season in Northern Ghana. German Development Cooperation (GIZ), Accra.

[23] GAIP (2012) Notification Report (ADVANCE Farmers-NR, UER \& UWR).

\section{Submit or recommend next manuscript to SCIRP and we will provide best service for you:}

Accepting pre-submission inquiries through Email, Facebook, LinkedIn, Twitter, etc. A wide selection of journals (inclusive of 9 subjects, more than 200 journals)

Providing 24-hour high-quality service

User-friendly online submission system

Fair and swift peer-review system

Efficient typesetting and proofreading procedure

Display of the result of downloads and visits, as well as the number of cited articles

Maximum dissemination of your research work

Submit your manuscript at: http://papersubmission.scirp.org/

Or contact ojbm@scirp.org 